\title{
Reinforcer and response specificity in appetitive transfer of control
}

\author{
DAVID J. BAXTER and EDWARD ZAMBLE \\ Queen's University, Kingston, Ontario, Canada
}

\begin{abstract}
Three experiments examine transfer from appetitive Pavlovian conditioning to appetitive instrumental responding by varying the similarity between conditions of Pavlovian reinforcement and instrumental reward. After conditioning with rats confined in a restraining device, a CS for electrical stimulation of the brain (ESB) produced substantial facilitation of operant responding for ESB, while a CS for food facilitated operant responding for food. However, no effects on rate of responding for food were seen during a CS for ESB. In a fourth experiment, four groups of rats were trained to barpress for rewarding electrical stimulation of the brain (ESB) and then given discriminative Pavlovian conditioning with ESB. The groups differed in the degree of similarity between the stimulus-response sequences present during Pavlovian conditioning and those occurring in instrumental responding. As similarity increased, so did the degree of conditioned facilitation in subsequent transfer tests. These results indicate that conditioned incentive responses or reinforcer-derived expectancies are specific to the conditions under which they develop, rather than generalized emotional or motivational responses.
\end{abstract}

Conditioned suppression of appetitive operant responding by an aversive Pavlovian conditioned stimulus is a relatively common and reliable phenomenon (e.g., Estes \& Skinner, 1941; Kamin, 1965; Rescorla, 1968). In contrast, the presentation of an appetitive CS during appetitive operant responding may produce conditioned suppression, conditioned acceleration, or no effect at all (Azrin \& Hake, 1969; Baxter \& Zamble, 1980; Bolles \& Grossen, 1970; Henton \& Brady, 1970; Herrnstein \& Morse, 1957; LoLordo, 1971; LoLordo, McMillan, \& Riley, 1974; Mackintosh, 1974; Meltzer \& Brahlek, 1970; Van Dyne, 1971). These contradictions are a serious problem for theories which assume Pavlovian mediation of instrumental responding (e.g., Bindra, 1974; Bolles, 1972; Rescorla \& Solomon, 1967).

Baxter and Zamble (1980), suggesting that much of the confusion may result from adventitious instrumental contingencies intruding into the transfer design, conducted four experiments in which rats were paralyzed with curare and given CS-ESB pairings. In subsequent tests, the CSs failed to produce any systematic changes in various baselines of operant responding for food, in spite of the fact that Zamble

This manuscript is based on portions of a thesis submitted by D. J. Baxter to the Psychology Department at Queen's University in partial fulfillment of the requirements of the PhD program. The research was supported by grants from the National Research Council of Canada to E. Zamble. The authors are indebted to Lynne Baxter for her assistance in all phases of this research and to Marilyn Hadad and Fred Bellemare for help with Experiments 2 and 3. Requests for reprints should be addressed to David J. Baxter, Research Department, Regional Psychiatric Centre, Correctional Service of Canada, P.O. Box 2500, Kingston, Ontario K7L 4Z4, Canada.
(1974) had obtained conditioned elevation of a baseline of general activity after virtually identical procedures.

We believe that this anomaly reveals a fundamental fault in the predictions of two-process learning theories. Conditioning with ESB leads to a capacity for the CS to increase an animal's state of activation, but fails to affect an instrumental response for food. Either there is some incompatibility between the anticipatory conditioned responses developed with food and with ESB, or there is a general problem in getting appetitive Pavlovian conditioned responses to affect appetitive instrumental responding.

The second alternative is unlikely considering the variety of ways in which Pavlovian procedures have been shown to affect instrumental behavior (e.g., Bower and Grusec, 1964; Estes, 1943; Trapold \& Winokur, 1967; Zamble, 1969). It must therefore be something specific to the design of Baxter and Zamble's (1980) experiments which prevents the occurrence of the expected transfer effects. Appeal to most theoretical formulations already in the literature provides little help, since they do not specify the nature of the conditioned incentive response and the precise manner in which it is supposed to affect instrumental responding.

It is possible, however, that a CS arouses a specific expectancy for the US, rather than some part of a completely general response or expectancy (Bindra, 1974; Bolles, 1972; Overmier, Bull, \& Trapold, 1971; Trapold, 1970; Trapold \& Overmier, 1972). A given response ought then to be controlled by the expectancy for the reward associated with it. It follows that responses controlled by different rewards may 
not be interchangeable, and that the confusion in the literature may result from the mixing of incompatible or unrelated expectancies in training and test situations.

This hypothesis suggests that positive transfer might occur only when the expectancies are compatible. It should be possible to obtain clear facilitation of appetitive operant behavior during a Pavlovian CS + when the US and the operant reinforcer are the same, but not necessarily when they are different-assuming, of course, that one uses procedures to control for superstitious learning during the Pavlovian conditioning stage. The first three experiments described below examined this prediction.

\section{EXPERIMENT 1}

In the studies reported here, animals were first trained on an instrumental response and then given Pavlovian conditioning; finally, the effects of the CSs on the operant response were tested. In the first experiment, rewarding ESB was the reinforcer for both the Pavlovian and the operant sessions.

\section{Method}

Subjects. The subjects were 10 naive male rats of the Fisher 344 strain (Charles River, COBS-CDF), weighing approximately $350 \mathrm{~g}$ at the start of the experiment. They were housed individually, with food and water always available in the home cages. Two additional subjects were discarded as a result of poor electrode placement.

Apparatus. The operant and testing sessions were conducted in Plexiglas boxes, $20 \times 25 \times 20 \mathrm{~cm}$ high, with wire grid floors. One wall of the box contained a nonfunctional food cup. Centered in the opposite wall were two response levers, protruding $4 \mathrm{~cm}$ into the chamber $5 \mathrm{~cm}$ apart and $11 \mathrm{~cm}$ above the floor. One of the levers remained in the chamber at all times (fixed bar); the other could be moved into or out of the box by a remotely controlled mechanism (retractable bar).

The boxes were enclosed in sound-attenuating chambers with dim constant illumination and a ventilating fan. A constant level of white noise was provided to supplement the noise of the fan in masking external sounds. Each chamber also contained a small speaker used for presenting auditory stimuli.

Brain stimulation was delivered by a $60-\mathrm{Hz}$ source, with output adjustable between 0 and $100 \mu \mathrm{A}$. The stimulator was connected to a mercury commutator mounted above the ceiling of the training box; spring-jacketed cable led from the commutator to the animal.

Pavlovian conditioning was carried out in a brightly lit soundattenuating chamber, $76 \times 45.5 \times 43.5 \mathrm{~cm}$ high. Ventilation and masking noise were provided, as in the test chambers. In the center of the chamber was a platform on which rested a semicircular Plexiglas restraining device, $8 \mathrm{~cm}$ in diameter at the base and adjustable from 12.5 to $18 \mathrm{~cm}$ in length. The front of the restrainer consisted of a trough for food delivery, not used in this experiment; the trough was partially separated from the rest of the restrainer by a divider which allowed limited access. A slit at the top of the restrainer accommodated the ESB cable. These restrainers permitted some restricted movement of the head or forepaws, but virtually no lateral or longitudinal movement.

Stimuli used in the experiment were a clicking noise ( 300 clicks/ min) and a 3,000-Hz tone, both adjusted to an intensity of 6-8 dB above background noise.
Procedure. Each subject was first anesthetized with an intraperitoneal injection of $60 \mathrm{mg} / \mathrm{kg}$ of sodium pentobarbital, and implanted with a bipolar electrode aimed at the lateral hypothalamus. One week was allowed for recovery following surgery.

Instrumental response training was then begun. Initially, animals were rewarded with a train of ESB lasting $.4 \mathrm{sec}$ for each response on the retractable bar. Bursts of stimulation were separated by at least $.4 \mathrm{sec}$. The intensity of the stimulation was adjusted until the animal maintained a steady rate of responding.

After approximately 300 reinforcements at the appropriate intensity, the rat was trained on a two-bar response. The retractable bar was first removed. Each response on the fixed bar was then rewarded by reinsertion of the retractable bar, which could be pressed for ESB reward. After 10 such rewards were delivered, the retractable bar was withdrawn until the next response was made on the fixed bar.

Over the next four to six daily $1-\mathrm{h}$ sessions, the reward schedule for the fixed bar was gradually extended to VI $90 \mathrm{sec}$, so that the overall schedule became a chain VI 90 -sec CRF (cf. Hawkins \& Pliskoff, 1964). This schedule was continued for 10 to 14 sessions. When necessary, ESB intensity was adjusted during this time to maintain a minimum rate of 300 responses/h on the fixed (VI) bar. Any animal failing to meet this criterion was discarded.

Beginning on the day following the final operant training session, all subjects were given two sessions of discriminative Pavlovian conditioning while confined in the restrainer. In each session there were 30 presentations each of the click and the tone, in a random sequence with a mean intertrial interval of $2.5 \mathrm{~min}$ and a minimum of $1 \mathrm{~min}$. For half the animals, the click was chosen as $\mathrm{CS}+$ and the tone was CS-; for the other subjects, the stimuli were reversed. The $\mathrm{CS}+$ was presented continuously for $10 \mathrm{sec}$, followed by a train of five .4-sec pulses of ESB, separated by $.4 \mathrm{sec}$, at the intensity used during the final operant session. Onset of the first ESB pulse was contiguous with the offset of CS+. The CS- was followed only by the interval before the next trial. The two conditioning sessions were separated by a day of rest and followed by a day of rest before the beginning of the test sessions.

The subjects were then given four transfer test sessions, in which $\mathrm{CS}+$ and CS- were presented on-line with operant responding. Each stimulus lasted $10 \mathrm{sec}$, and both $\mathrm{CS}+$ and CS - were presented 10 times during each session. The stimuli were presented in a random sequence with a mean intertrial interval of $3 \mathrm{~min}$ and a minimum of 1 min. The CS + was not followed by ESB during testing. Barpressing was rewarded on the chain VI CRF schedule, as in operant training, except that the retractable bar could not be inserted during the period from $10 \mathrm{sec}$ preceding a CS to $5 \mathrm{sec}$ after CS termination. If the retractable bar was in the chamber when a trial was scheduled, onset of the stimulus was delayed until at least $10 \mathrm{sec}$ after retraction.

\section{Results}

After the first few days of operant training, no subject required priming or shaping at the beginning of a session. All subjects exhibited considerable excitement when brought to the experimental area, and began responding immediately when placed into the box. Rates on the fixed (VI) bar ranged from 360 to 683 responses/ $h$ during the last few operant training sessions. Response rates on the retractable (ESB) bar were consistently higher than the minimum requirement, ensuring the maximum rate of stimulation in virtually every instance.

Responses from the periods immediately preceding and during CS presentations were used to calculate change ratios (Annau \& Kamin, 1961). For this sta- 


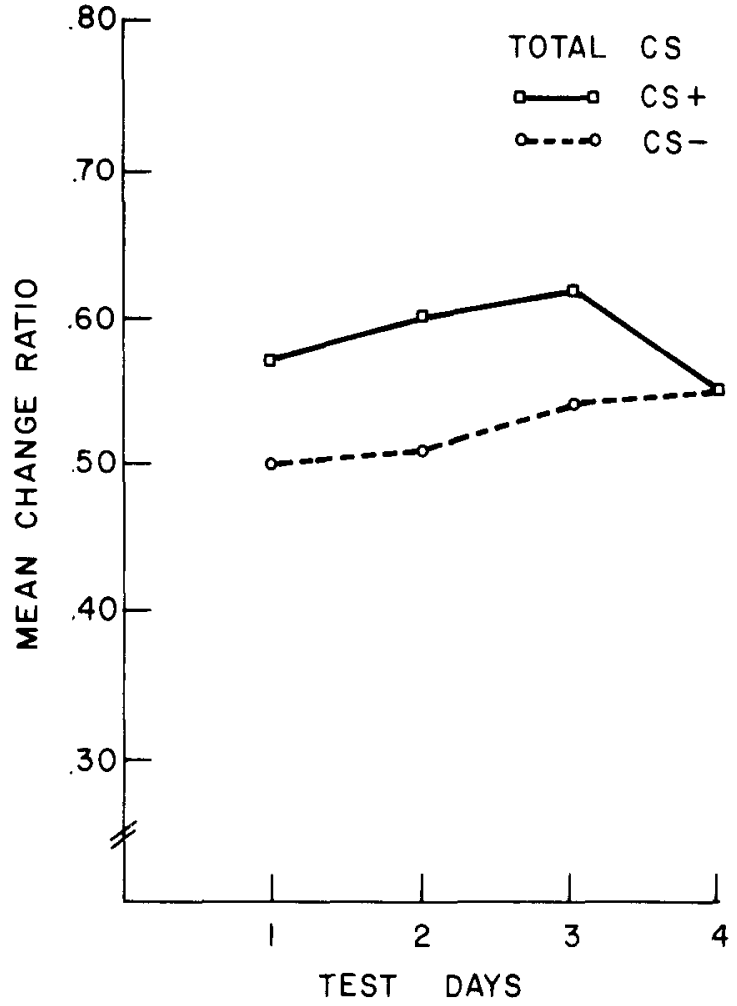

Figure 1. Mean change ratios for CS+ and CS- in Experiment 1.

tistic, a value of .50 indicates no effect of CS presentation on response rate; values greater than .50 represent increases in response rate; and values less than .50 indicate decreases in response rate during the CS.

The mean change ratio for each CS across test sessions is shown in Figure 1. There was an elevation in responding during $\mathrm{CS}+$ for the first three sessions, but no changes were apparent during CS-. A twofactor repeated measures analysis of variance verified the overall difference between CS + and CS - with a significant $C S$ main effect $[F(1,9)=8.62, p<.05]$. No other term in the analysis approached significance.

Further analyses by $t$ tests confirmed the trends visible in the figure. The change ratios for $\mathrm{CS}+$ were significantly greater than .50 in Sessions 1 to $3[\mathrm{t}(9)=$ $2.64,5.94,3.22$, respectively; $p<.05$ ]. Change ratios for CS- did not differ significantly from .50 in any session.

\section{Discussion}

These results demonstrate that a Pavlovian signal for ESB can produce reliable acceleration of operant responding for an appetitive reward. In fact, the observed changes may be less than the degree of conditioned acceleration that can actually occur during CS +. Intermittent visual observations of animals during test sessions suggested that they exhibited inhibition of delay during $\mathrm{CS}+$ presentations: there was often little change in response rate or even a tem- porary halt in responding at the beginning of the stimulus, followed by an increase during the latter part of the CS. The procedures in Experiment 1 did not allow assessment of this effect, but we may infer that the increase of responding during the latter part of the CS+ was even greater than shown in Figure 1.

In any case, these results support theoretical expectations, but they are in contrast with the failures to find clear facilitation discussed above (Baxter \& Zamble, 1980). The following two experiments varied reinforcer combinations to provide further information on the role of reinforcer relationships in transfer.

\section{EXPERIMENT 2}

This study attempted to duplicate the design of Experiment 1 as far as possible, with one important difference: the reward for the baseline of instrumental behavior was, in this case, food. Positive results would indicate that previous lack of transfer with a food-response baseline was the result of procedural inadequacies. However, a lack of positive transfer would confirm the earlier experiments and indicate the importance of US-reinforcer similarity.

\section{Method}

Subjects. Ten male albino rats (Fisher 344), weighing approximately $30 \mathrm{~g}$ at the beginning of the experiment, were used. They were placed on a 22.5-h food deprivation schedule and reduced to $80 \%$ of ad-lib body weight prior to the beginning of training. Water was freely available in the home cage at all times. An additional seven rats were discarded because of failures to pass selfstimulation tests, or because of apparatus malfunctions during the test sessions.

Apparatus. The operant training and transfer tests were conducted in a set of four boxes. Two of these were made of aluminum and Plexiglas, $25 \times 22 \times 20 \mathrm{~cm}$ high, with wire grid floors. A single response lever protruded from the center of one wall; on the opposite wall was a food cup, to which $45-\mathrm{mg}$ food pellets could be delivered. The other two boxes were constructed similarly, except that they were made entirely of Plexiglas. The boxes were enclosed in sound-attenuating chambers and were dimly lit at all times.

The screening pretest for self-stimulation was conducted in a Plexiglas box, $26.5 \times 30.5 \times 22 \mathrm{~cm}$ high, situated in a quiet room with bright illumination. The posttest was conducted in the twobar boxes used in Experiment 1.

Procedure. Surgical procedures were identical to those used in Experiment 1. After a week's recovery from surgery, each rat was given a pretest for self-stimulation. Pulses of ESB were delivered contingent on an animal's poking its nose into an arbitrarily selected corner of the box, and current intensities were adjusted until a steady rate of responding was maintained for approximately 300 reinforcements. This response was chosen because it was well defined and convenient to record, and because it was different from the barpressing response used in later training; posttests (described below) were conducted using the more conventional barpressing response. Subjects failing to respond steadily within the range of current intensities used $(20-100 \mu \mathrm{A})$ were discarded.

The animals were then trained to barpress for food. After an initial session with a CRF reward schedule, they were gradually introduced to a VI 90-sec schedule. Each rat was given 10-14 daily 1-h sessions on the VI schedule to allow response rates to stabilize. 
Next, subjects were given two discriminative Pavlovian conditioning sessions while they were confined in the restraining device. The procedures were the same as those in Experiment 1.

Conditioning was followed by four transfer test sessions. The $\mathrm{CS}+$ and CS- were each presented alone 10 times per session. Barpressing was rewarded on the VI schedule used in operant training, except that food rewards were not delivered during the period starting $10 \mathrm{sec}$ before CS onset and ending $5 \mathrm{sec}$ after the end of the CS. Responses were recorded for the two 5 -sec periods immediately preceding CS presentation, and for the first and last $5 \mathrm{sec}$ of the CS. Thus, the procedure for the test was like that used in Experiment 1, except for the use of food rewards instead of ESB to maintain the operant response baseline.

Finally, the animals were placed in the two-bar boxes and trained to barpress for ESB on a CRF schedule. Responses on either bar were rewarded at the current intensity determined in the pretest and used during Pavlovian conditioning. Any subject failing to meet a criterion of 1,000 responses/ $h$ was retested $24 \mathrm{~h}$ later. If the criterion was not met on the second day, the subject was discarded from the experiment.

\section{Results}

The data were converted to two different change ratios. The first was based on the full 10 -sec CS period, as in Experiment 1. The second was computed similarly, except that only those responses occurring during the last $5 \mathrm{sec}$ of a CS were considered; this ratio is referred to as CS(end). The second statistic was expected to maximize the visibility of CS effects in the event that inhibition of delay occurred during the CS.

Figure 2 shows the mean change ratios in each test session calculated for CS(end). An analysis of variance revealed significant differences between $\mathrm{CS}+$ and $C S-[F(1,9)=9.23, p<.05]$. The days effect in the analysis was also significant $[\mathrm{F}(3,27)=3.29, \mathrm{p}<$ .05], apparently reflecting a small decline in the values for both CSs as testing continued. Results for the ratio for the total CS were essentially the same

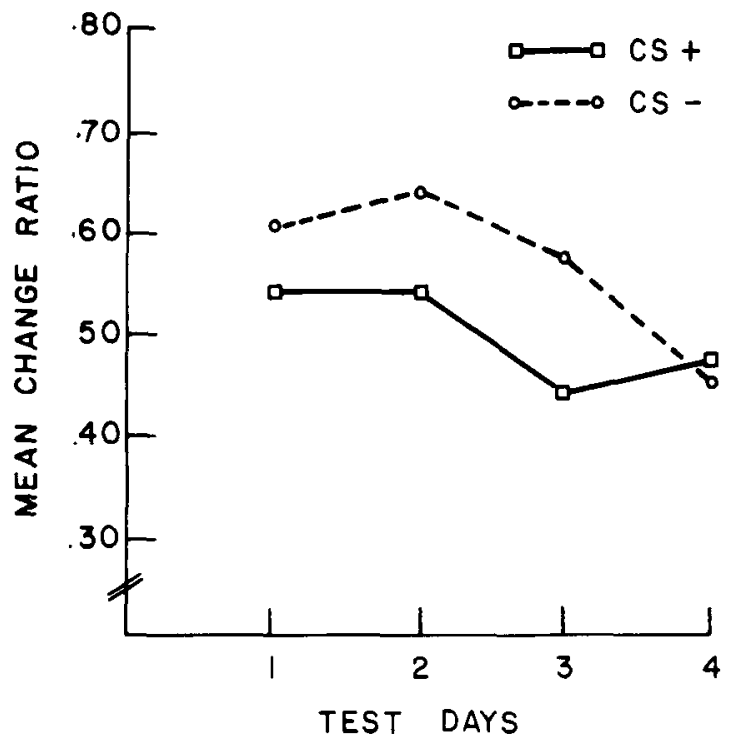

Figure 2. Mean change ratios for CS+ and CS- in Experiment 2. [for the CS effect, $F(1,9)=12.55, p<.01$ ], except that the days effect was not significant $(F<1)$.

Subsequent $t$ tests showed that response rates during CS+ did not change significantly from baseline for any of the test sessions for either of the two change ratios, confirming the results of Baxter and Zamble (1980). Surprisingly, response rates were significantly elevated during CS- for the first two test days $[\mathrm{t}(9)=2.41$ and 3.00 , respectively; $\mathrm{p}<.05]$.

\section{Discussion}

Despite several procedural differences, the results of this experiment confirm those of earlier attempts (Baxter \& Zamble, 1980) in two respects. First, there was no evidence of conditioned facilitation of instrumental responding for food during a $\mathrm{CS}+$ for rewarding ESB. Second, presentation of CS- produced some acceleration of responding in both cases, although this effect did not reach statistical significance levels in the earlier studies. This result is not predicted by any present theoretical position, and, indeed, we can suggest no explanation for it at this time.

Taken together, the first two experiments show that a $\mathrm{CS}+$ for brain stimulation will facilitate responding if the subject is working for brain stimulation, but not if it is responding for food. We believe that the CS+ in Experiment 2 did not affect operant responding because it signaled an event that was not relevant to the operant response or because it elicited a pattern of behavior not compatible with the operant response. If this is so, conditioned acceleration should be obtained not only when the US and operant reward are both ESB, but also when they are both food. Experiment 3 examined this prediction and served as a further check on the procedures.

\section{EXPERIMENT 3}

In this experiment, the operant reward and the Pavlovian US were the same, as in Experiment 1. However, in this case they were both food rather than ESB. The general procedures were similar to those of the preceding experiments, except that subjects did not receive electrode implantations.

\footnotetext{
Method

Subjects. The animals in this study were 10 male albino rats of the Fisher 344 strain, weighing approximately $300 \mathrm{~g}$ at the start of the experiment. As in Experiment 2, they were placed on a 22.5-h food-deprivation schedule and reduced to $80 \%$ of ad-lib body weight prior to the start of training; water was freely available in the home cage at all times. One additional rat was discarded as a result of apparatus malfunction during the test sessions.

Apparatus. The apparatus for operant training and transfer tests and that for Pavlovian conditioning were the same as those used in Experiment 2, except that the cables for delivery of ESB were omitted. A small plastic tube was connected to the food trough at the front of the restrainer, through which 45-mg pellets were delivered from an automatic dispenser.
} 
Procedure. The subjects were first trained to barpress for food reward, and given a minimum of 121 -h sessions of responding on the VI 90 -sec schedule, as in Experiment 2. The animals were then given discriminative Pavlovian conditioning sessions, as in Experiments 1 and 2 . The US was a single $45-\mathrm{mg}$ food pellet delivered into the food trough of the restrainer at the termination of CS+. Finally, subjects were given four transfer test sessions, in which the CSs were presented while the operant schedule was in effect. The procedures were the same as those used in Experiment 2.

\section{Results}

As in Experiment 2, the primary measure of CS effects was based on response rates during the last $5 \mathrm{sec}$ of CS presentations, termed CS(end). Figure 3 shows the results for CS+ and CS- over test days.

An analysis of variance for the CS(end) ratios indicated that the subjects exhibited discrimination between $C S+$ and $C S-[F(1,9)=15.23, p<.01]$. Other terms in the analysis did not approach significance. Analyses using rates from the total CS period showed much the same pattern [CS effect, $F(1,9)=5.79$, $\mathrm{p}<.05$ ], except that the ratios for $\mathrm{CS}+$ were generally smaller than those based on only the last $5 \mathrm{sec}$.

Using the CS(end) ratio, $t$ tests were used to test whether values for $\mathrm{CS}+$ and $\mathrm{CS}-$ were different from .50. These showed significant increases for $\mathrm{CS}+$ on Test Days 1 and $3[\mathrm{t}(9)=3.73, \mathrm{p}<.01$, and $t(9)=2.49, p<.05$, respectively]. On Day 2, the $t$ value was not significant $[\mathrm{t}(9)=1.71]$, although the mean was about the same. The ratios for CS- did not differ significantly from .50 in any test session.

\section{Discussion}

The results of Experiment 3 confirm those of Experiments 1 and 2. A signal for ESB accelerates operant responding for ESB, and a signal for food accelerates responding for food, but a signal for ESB

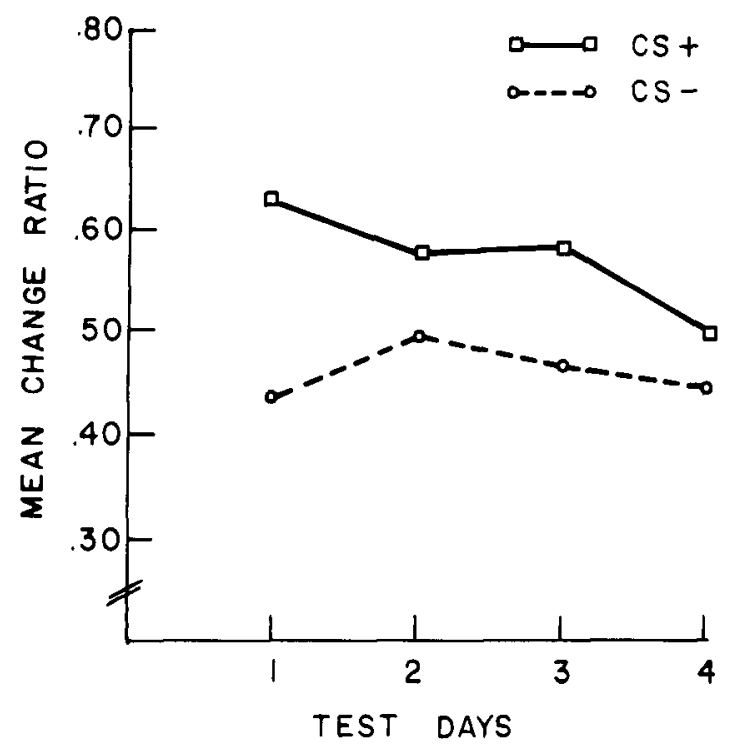

Figure 3. Mean change ratlos for CS+ and CS- in Experiment 3. has no reliable effects on responding for food despite the use of virtually identical conditioning procedures throughout.

A reexamination of Azrin and Hake's (1969) experiments on positive conditioned suppression provides some further support for these findings. There were five groups of rats in the Azrin and Hake study. For three groups, the US and operant reward were dissimilar: the combinations used were ESB and food, food and water, and water and food. All of these subjects showed conditioned suppression of responding during the CS. For the remaining two groups, the US and operant reward were qualitatively, though not quantitatively, the same. One of these groups (water and water) showed conditioned acceleration of responding; the other group (food and food) showed conditioned suppression, but the degree of suppression was smaller than that for the first three groups. Bearing in mind that Azrin and Hake conducted their conditioning sessions on-line with operant responding, where the possibility of intrusive adventitious instrumental learning would be maximized, their results are remarkably in agreement with the current results.

Having produced evidence of positive transfer, we feel that we are faced with the anomaly of having to justify a predicted result in the light of a great number of unsuccessful or ambiguous previous results. For a number of years, it has been widely known that the demonstration of response facilitation in a simple transfer design was elusive, with a variety of unsuccessful and unpublished efforts in many laboratories. Several authors have commented on this inconsistency, or offered possible explanations for it (e.g., Bindra, 1974; Trapold \& Overmier, 1972).

We believe that several factors contribute to response facilitation in the appetitive case. First, it is helpful either to restrict subjects' movements during Pavlovian trials by curarization or physical restraints, or to manipulate these movements as an experimental variable (e.g., Trapold \& Carlson, 1965). In the absence of such restrictions, it is possible that animals will develop movement patterns which will be different from those in the instrumental response being measured.

These behaviors may be acquired by adventitious reinforcement of responses occurring spontaneously in the experimental situation (i.e., superstitious learning), or they may be directly energized (elicited) by the unconditioned stimuli employed (i.e., adjunctive behaviors: Staddon \& Simmelhag, 1971). In either case, the responses will come under the control of the Pavlovian CSs used, and will occur during tests of transfer as part of the response to the CS, probably resulting in modification of the instrumental response (cf. Bower \& Kaufman, 1963). If the adventitious behaviors are very similar to the instrumental behavior, conditioned facilitation of operant 
responding might well be observed; when these behaviors are very different from the instrumental response, they will probably interfere with instrumental performance. Without prior knowledge of such effects, the nature of transfer cannot be predicted with any confidence in experiments using subjects whose movements are not restricted or experimentally controlled.

Although the introduction of movement restrictions is desirable, it is not sufficient for the appearance of response facilitation (Baxter \& Zamble, 1980). The current results suggest the generalization that facilitative transfer will occur when the operant reward is qualitatively similar to the US, or when the US and operant reward are compatible, but not in any predictable way when the US and the operant reward are different and incompatible.

Two-process and conditioned incentive theorists have generally assumed that appetitive reward systems are more or less interchangeable in affecting some sort of central emotional-motivational ("emotive") state (cf. Rescorla \& Solomon, 1967). As these experiments indicate, this is not universally true. It is clear, at least in the conditions described here, that the responses for ESB and for food are not interchangeable. A CS for ESB may have an excitatory effect on a subject (Zamble, 1974), but that excitement appears to be irrelevant to the factors controlling responding for food. Differences in the anticipations for other positive reinforcers have also been suggested (e.g., Hearst, 1975; Jenkins \& Moore, 1973; Konorski, 1967), and similar relationships have been reported for aversive reinforcers. For example, the rate of operant avoidance responding maintained by electric shock is typically enhanced by presentation of a Pavlovian CS for shock (e.g., Rescorla \& Solomon, 1967; Trapold \& Overmier, 1972), but this effect can be modified by qualitative or quantitative differences in the shocks used as the US and operant reinforcer. Thus, Scobie (1972) reported that a CS for strong shock suppressed avoidance responding maintained by a weak to moderate shock, while Barbaree and Weisman $(1975,1978)$ found that rate of footshock avoidance responding was accelerated by presentation of a CS for footshock, but not by a CS for tailshock. Such findings imply that the nature of the conditioned response is determined quite specifically by the choice of the US.

The results of the present experiments are thus compatible with previous suggestions that subjects develop expectancies for different reinforcers in addition to, or perhaps instead of, nonspecific emotive states (Overmier, Bull, \& Trapold, 1971; Trapold, 1970; Trapold \& Overmier, 1972). Although the concept of "expectancy" is not usually explicitly defined, its use implies that it refers to a central component or representation of the conditioned response which develops with a given reinforcer (Bindra, 1974; Bolles, 1972; Trapold \& Overmier, 1972). On this basis, we can probably say that all expectancies have the potential to affect responding, but not that they will affect all responding in the same way; the effects may be modified by interaction with other expectancies controlling ongoing responding.

It is not necessarily the case that facilitation will occur only when the US and the operant reward are identical. We would expect, for example, that qualitative differences between the reinforcers are generally of greater importance than quantitative differences, but in some cases transfer appears to be just as sensitive to quantitative relationships between the US and the operant reinforcer (Scobie, 1972; Wielkiewicz, 1979). Moreover, facilitation might occur even when qualitative differences exist, provided that the CS signals a US that is relevant to the operant reward, or that the behaviors generated by the Pavlovian and operant expectancies are complementary. As these experiments demonstrate, we need a detailed description of the properties of conditioned emotive states or expectancies. Without this, we cannot infer the point at which the incompatibility between different reinforcers manifests itself, largely because we have no clear understanding of the behavioral properties of the conditioned anticipatory states themselves. Experiment 4 is an attempt to provide some of this detail.

\section{EXPERIMENT 4}

On the basis of Experiments 1-3, we may argue that the conditioned response affecting instrumental responding is at least partly specific to the Pavlovian reinforcer used. We believe that the specificity of transfer is a result of the specificity of behaviors occurring in anticipation of the reinforcers. In many cases, a particular reinforcer or the expectation of a particular reinforcer generates approach and consummatory responses which are more or less unique to that reinforcer (Hearst, 1975; Jenkins \& Moore, 1973; Konorski, 1967; Pavlov, 1927; Peterson, Ackil, Frommer, \& Hearst, 1972; Wolin, 1968; Zener, 1937). In the transfer-of-control experiment, such responses would be elicited by the presentation of Pavlovian CSs as well as cues arising from instrumental responding. Thus, the results of a transfer procedure will depend on the similarity between responses evoked by the expectancy for the Pavlovian reinforcer and responses evoked by the expectancy for the instrumental reward: if the reinforcers are very different, the responses generated will also be very different and will likely compete with one another in a transfer test.

Other variables which affect the similarity of the response sequences in Pavlovian and instrumental stages should also affect transfer (Trapold \& Overmier, 1972). For example, the similarity between the Pavlovian CS and discriminative stimuli in the operant setting $\left(S_{D} s\right)$ should be a factor, since similar 
stimuli will more easily combine to control the response sequence occurring during the test of transfer, that is, generalization from one set of stimuli to the other will be more readily effected. Similarity between response sequences in the Pavlovian and instrumental stages should work in the same way, for the greater the similarity, the greater the likelihood that the two behaviors will be easily integrated to produce a sequence identifiable as conditioned facilitation (cf. Bower \& Kaufman, 1963; Trapold \& Carlson, 1965). As the similarity of the Pavlovian and instrumental response sequences increases, they subsume more elements of each other; therefore, behavior generated by the CS should work its way more quickly into the instrumental chain and modulations in the instrumental baseline should become evident at an earlier point in testing. The magnitude of the transfer effect might also increase because, as transfer occurs more quickly, it will occur at an earlier point in extinction of the Pavlovian CR, that is, at a point at which the expectancy aroused by the CS is stronger.

Experiment 4 examined some implications of this analysis. Animals were first trained to barpress for rewarding ESB, using a two-bar chaining procedure. They were then given discriminative Pavlovian conditioning with rewarding ESB. During conditioning, the correspondence between the Pavlovian response sequence and its instrumental counterpart was manipulated by varying background cues and cues controlling responding. Finally, the CSs were presented in a transfer test during performance of the operant response.

\section{Method}

Subjects. The subjects were 40 naive male albino rats (Fisher 344 strain) weighing 275 to $350 \mathrm{~g}$ at the beginning of the experiment. They were allowed unrestricted access to food and water in the home cage throughout the experiment. Six other rats were discarded as a result of apparatus malfunction or poor electrode placement.

Apparatus. The operant and testing sessions were conducted in the two-bar boxes used in Experiment 1. For some of the animals, Pavlovian conditioning was carried out using the restrainers in the Pavlovian chamber described in Experiment 1. The remaining animals received Pavlovian trials in the boxes used for operant training. Brain stimulation was delivered by a $60-\mathrm{Hz}$ source, with output adjustable between 0 and $100 \mu \mathrm{A}$. The stimulator was connected to a mercury commutator mounted above the ceiling of the training box; spring-jacketed cable led from the commutator to the animal.

Stimuli used in the experiment were a clicking noise $(300$ clicks/min) and a $3,000-\mathrm{Hz}$ tone, both adjusted to an intensity of 6-8 $\mathrm{dB}$ above background noise.

Procedure. Each subject was first anesthetized with an intraperitoneal injection of $60 \mathrm{mg} / \mathrm{kg}$ of sodium pentobarbital, and implanted with a bipolar electrode aimed at the lateral hypothalamus. One week was allowed for recovery from surgery. Instrumental response training was then begun. Initially, animals were rewarded with a train of ESB lasting .4 sec for each response on the retractable bar. Bursts of stimulation were separated by at least $.4 \mathrm{sec}$. The intensity of the stimulation was adjusted until the animal maintained a steady rate of responding.

After approximately 300 reinforcements at the appropriate intensity, the rat was trained on the two-bar response used in Experi- ment 1 . First, each response on the fixed bar was rewarded by insertion of the retractable bar, which could then be pressed for ESB reward. After 10 such rewards were delivered, the retractable bar was withdrawn until the next response on the fixed bar (Hawkins \& Pliskoff, 1964).

Over the next four to six daily 1-h sessions, the reward schedule for the fixed bar was gradually extended to VI $90 \mathrm{sec}$ (actually, chain VI 90-sec CRF). This schedule was continued for 10 to 14 sessions. When necessary, ESB intensity was adjusted during this time to maintain a minimum rate of 300 responses $/ h$ on the fixed (VI) bar. Any animal failing to meet this criterion was discarded.

Subjects were then assigned randomly to one of four groups of 10 subjects each, and given two discriminative Pavlovian conditioning sessions, with a day's rest following each session. There were 30 presentations of $\mathrm{CS}+$ and 30 of CS- in each session, with the stimuli occurring in a random sequence with a mean ITI of $3 \mathrm{~min}$ and a range of 90 to $270 \mathrm{sec}$. The stimuli were counterbalanced so that the tone was the CS+ for half the subjects in each group and the click was the CS+ for the other animals. The CSs were presented for $10 \mathrm{sec}$ on every trial.

The remaining conditioning procedures differed for the four groups. For Group N/R (noncontingent and restrained), the subjects were confined in Plexiglas restrainers during Pavlovian conditioning, as described above. The termination of $\mathrm{CS}+$ coincided with the beginning of a train of five .4-sec pulses of ESB, with successive pulses separated by $.4 \mathrm{sec}$, at the intensity used in the final operant training sessions. The termination of CS- was followed by a minimum period of $90 \mathrm{sec}$ before the start of the next trial.

For Group $\mathbf{N} / \mathrm{U}$ (noncontingent and unrestrained), conditioning was conducted in the operant chamber. The animals were allowed unrestricted movement around the box, but both bars were removed completely before the beginning of each session. In all other respects, training was identical to that of the first group. Thus, the cues in the operant box provided part of the CS complex for animals in this group, in contrast to the first group.

For Group N/BI (noncontingent with bar insertion), subjects were also permitted unrestricted movement in the operant box during conditioning. The fixed bar was removed from the box throughout the Pavlovian sessions, but the retractable bar was inserted as the first pulse of ESB began at the termination of CS+. Responses on this bar had no effect, however, and the bar was withdrawn again immediately following the last ESB pulse on each trial. All other training conditions were identical to those of Group N/U. Thus, the CS complex for this group included insertion of the retractable bar, so that the cues for the Pavlovian response were very similar to the $S_{\mathrm{D}}$ s for approach and consummatory barpressing during instrumental responding.

Subjects in Group C (contingent) were given a modified Pavlovian conditioning sequence. Procedures were identical to those of Group N/U, except that termination of a CS + was immediately followed by insertion of the retractable bar. The animals were then required to barpress to receive the five pulses of ESB, delivered on a CRF schedule with the restriction that successive pulses of ESB were separated by at least $.4 \mathrm{sec}$. The bar was withdrawn again as the final pulse of ESB was delivered. In one sense, this might be considered a departure from the usual response-independent Pavlovian conditioning procedures. However, it can be argued (cf. Hawkins \& Pliskoff, 1964; Pliskoff, Wright, \& Hawkins, 1965) that this requirement in fact makes conditioning with ESB more similar to conditioning with conventional reinforcers. That is, barpressing for ESB is analogous to the normal consummatory responses necessary with a food or water US. The procedure also served to equate both stimulus and response factors in the Pavlovian UR and CR with those in the terminal components of the instrumental chain.

Finally, after a day's rest following the second Pavlovian conditioning day, subjects were given four transfer test sessions, in which CS + and CS- were presented on-line with operant responding. Each stimulus lasted $10 \mathrm{sec}$, and both CS+ and CS- were presented 10 times during each $1-\mathrm{h}$ session. The stimuli were presented 
in a random sequence with a mean intertrial interval of $3 \mathrm{~min}$ and a minimum one of $1 \mathrm{~min}$. The CS + was not followed by ESB during testing. Barpressing was rewarded on the chain VI CRF schedule, as in operant training, except that the retractable bar could not be inserted during the period from 10 sec preceding a CS to $5 \mathrm{sec}$ after CS termination. If the retractable bar was in the chamber when a trial was scheduled, onset of the stimulus was delayed until at least $10 \mathrm{sec}$ after retraction.

\section{Results}

Responses from the periods immediately preceding and during CS presentations were used to calculate change ratios, as in Experiments 2 and 3, with one ratio based on the full $10 \mathrm{sec}$ of CS presentation and the other based only on the final $5 \mathrm{sec}$ of a CS. Both ratios were subjected to analysis of variance.

The results were substantially the same for the two ratios, except that the effects tended to be enhanced with the ratio based on the last $5 \mathrm{sec}$; accordingly, only the CS(end) ratio is discussed here. Ratios for Groups N/R, N/U, N/BI, and C are shown in Figure 4.

Two major results visible in the figure were confirmed by the analysis of variance. First, subjects showed clear discrimination between $\mathrm{CS}+$ and $\mathrm{CS}-$, as evidenced by a significant main effect for CSs $[F(1,36)=28.05, p<.001]$. Second, the differences between $\mathrm{CS}+$ and $\mathrm{CS}$ - increased over the four test sessions, as evidenced by a significant $\mathrm{CS} \times$ days interaction $[F(3,108)=5.33, p<.01]$.

The analysis of variance, including both $\mathrm{CS}+$ and CS- showed no significant differences among groups $[F(3,36)=2.54]$ and no $C S \times$ groups interaction $[F(3,36)=1.26]$. However, the data suggested that all the changes in operant response rate occurred

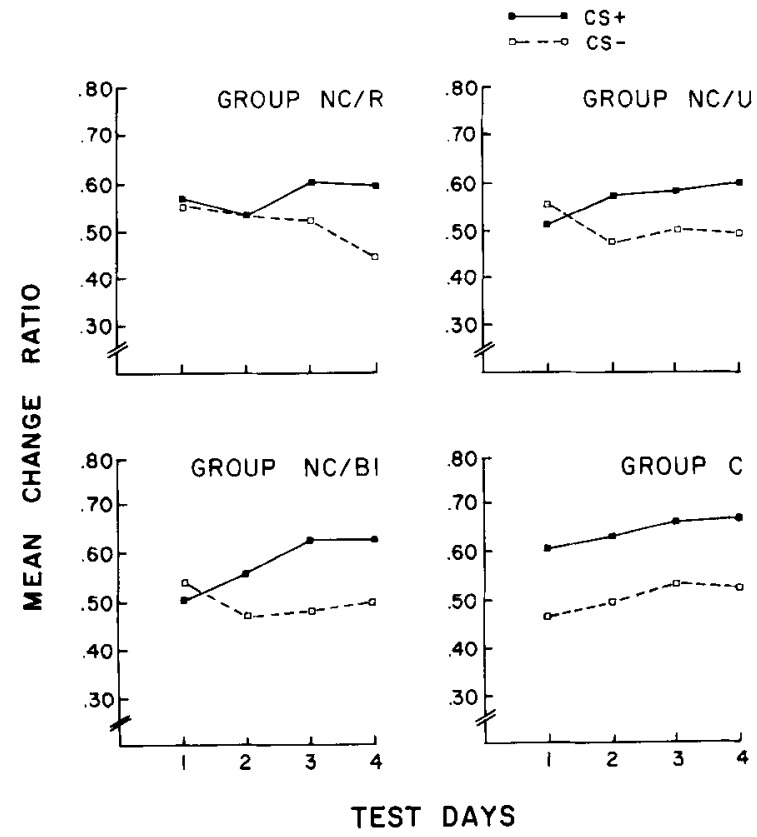

Figure 4. Mean change ratios for CS+ and CS- for Groups $N / R, N / U, N / B I$, and $C$ in Experiment 4. during presentation of the $\mathrm{CS}+$; therefore, a second analysis of variance was conducted examining only the change ratios for $\mathrm{CS}+$. This analysis indicated that the degree of conditioned acceleration during CS + increased across test days $[F(3,108)=6.88$, $\mathrm{p}<.001]$, and that there were significant differences between groups in the amount of facilitation produced by $\mathrm{CS}+[\mathrm{F}(3,36)=3.52, \mathrm{p}<.05]$.

The obtained change ratios for each CS were then compared with a value of .50 , representing no change in response rates, using $t$ tests. These tests showed that the CS+ produced significant acceleration of responding in all four groups, at the .05 level of significance or better, on at least 3 of the 4 test days. In contrast, presentation of CS- had no significant effects on response rate.

An estimate of total magnitude of transfer was then obtained by calculating the mean change ratio for each subject over all 4 test days: in essence, this is an estimate of the total area under the curve for $\mathrm{CS}+$. A one-way analysis of variance on these data showed significant differences among the groups $[F(3,36)=3.55, p<.05]$. Orthogonal comparisons showed, first, that Pavlovian conditioning under restraint and in a different environment (Group N/R) did not significantly affect magnitude of transfer as compared with conditioning without restraint in the operant environment (Groups N/U, N/BI, and C combined): this comparison did not reach statistical significance levels $[F(1,36)=1.44]$. Second, for groups given conditioning in the operant environment, accompanying US presentations during conditioning by a cue serving as a discriminative stimulus in the operant chain, viz, insertion of the ESB bar (Group N/U vs. Groups N/BI and C combined), increased magnitude of transfer $[F(1,36)=3.97$, $\mathrm{p}<.05]$. Third, for groups given the discriminative cue during the US, requiring a consummatory response to obtain the US (Group N/BI vs. Group C) also significantly increased magnitude of transfer $[\mathrm{F}(1,36)=5.24, \mathrm{p}<.05]$.

Finally, an estimate of speed of transfer was obtained by determining the point at which each group first demonstrated discrimination between CS+ and CS-, defined as the point at which the difference between the CSs became significantly greater than zero. For Group N/R, this difference was not significant until Day $4[t(9)=2.41, p<.05]$. For Group N/U, the difference was significant on Days 2,3 , and 4 [respectively, $t(9)=3.13,1.87,2.77 ; \mathrm{p}<.05]$. For Group N/BI, the difference was also significant on Days 2, 3, and 4 [respectively, $t(9)=2.88,2.27,2.13$; $\mathrm{p}<.05]$. Finally, for Group $\mathrm{C}$, the difference was significant on all 4 test days [respectively, $t(9)=2.16$, $2.51,2.57,2.63 ; \mathrm{p}<.05]$.

\section{Discussion}

All subjects in this experiment showed conditioned acceleration of operant responding during the CS + . 
Although acceleration occurred following four different Pavlovian conditioning procedures, in each case the CS had previously signaled a US which was qualitatively identical to the operant reward. This finding confirms the results of Experiments 1-3, adding weight to the hypothesis that consistent appetitive transfer effects are easily obtained when the Pavlovian and instrumental reinforcers are very similar. In contrast, there were no significant effects of $\mathrm{CS}$ presentation, again confirming the results of the earlier experiments.

It was predicted that the magnitude of response facilitation and/or the speed with which transfer became apparent would increase as the stimulus situation and response requirements of Pavlovian conditioning became more similar to those in the instrumental baseline; differences in transfer among groups in this experiment provide some support for those predictions. As Figure 4 shows, there was an increasing gradient across the four groups in the value of the change ratios for $\mathrm{CS}+$. This was primarily attributable to the addition of cues for instrumental responding and part of the operant sequence within the Pavlovian CS-CR complex, rather than any difference between the restrained and unrestrained conditions, which did not in itself significantly affect transfer. There was also a progressive gradient in speed of transfer from Group N/R through Groups $\mathrm{N} / \mathrm{U}, \mathrm{N} / \mathrm{BI}$, and $\mathrm{C}$, as predicted. In general, the greater the similarity between the Pavlovian and instrumental situations, the earlier was transfer visible. Thus, Group C showed significant facilitation of responding during CS+ on the 1st day of testing, while this did not occur until the 4th day for Group N/R.

These results support the hypothesis that the degree of transfer is a function of (1) the degree to which behaviors elicited by Pavlovian conditioning overlap with, or are compatible with, components of the chain of instrumental behavior, and (2) the degree to which the stimuli controlling the Pavlovian behaviors are similar to, or are compatible with, stimuli controlling the instrumental chain.

One might question this interpretation on the grounds that the procedures for three of the groups failed to include controls for adventitious reinforcement (Baxter \& Zamble, 1980; Trapold \& Overmier, 1972 ) and that an explanation based on instrumental learning could account for the observed ordering of the groups (Bower \& Kaufman, 1963). Although it is probably impossible to ever refute this criticism entirely, even with the use of curare paralysis (Black, 1967; Trapold \& Overmier, 1972), it is not consistent with the details of our findings in this study. First, the lever on which responding during transfer tests was measured was never present in the chamber during Pavlovian conditioning. This eliminated the possibility that transfer effects were mediated by direct reinforcement of the baseline instrumental response per se, although other components of the instrumental chain were of course permitted. Second, the ESB bar, inserted for some subjects during conditioning, was separate and displaced from the VI bar. Thus, direct reinforcement of behaviors directed towards the ESB bar could have occurred, but this should have drawn the animal away from the VI bar during the $\mathrm{CS}+$, thereby reducing rather than increasing response rates during transfer tests. Third, if transfer was mediated by reinforcement of instrumental behaviors, one would expect clear differences between the restrained Group N/R, with conditioning conducted in a different environment, and the other three unrestrained groups, with Pavlovian training in the operant chamber. No such differences were found.

The results are in conflict with a general emotive state model of transfer of control (e.g., Rescorla \& Solomon, 1967). Such theories would not predict differences in speed or magnitude of transfer, because transfer is assumed to be an automatic and immediate process. Transfer, according to these theories, should have been identical for all groups because it followed Pavlovian training which was the same for each group in all the fundamental CS-US parameters. On the other hand, these results are consistent with an analysis of transfer based on expectancy theories (e.g., Bolles, 1972; Trapold \& Overmier, 1972).

During Pavlovian conditioning, an organism acquires an expectancy which leads to the establishment of a conditioned response. Regardless of how or why the conditioned response occurs, it becomes an element of the organism's experience with the conditioned and unconditioned stimuli. Similarly, instrumental training produces an expectancy which is established in the presence of specific environmental cues $\left(\mathrm{S}_{\mathrm{D}} \mathrm{s}\right)$. Thus, in both cases, the organism is exposed to and acquires information about a sequence of events that includes environmental stimuli, a sequence of behavior, and a reinforcer.

In these terms, the transfer-of-control experiment is a procedure in which the Pavlovian expectancy is superimposed upon expectancies operating in the instrumental setting. If conditioned facilitation occurs, it must do so because the two expectancies have combined in some form of mutual augmentation. Whether this will happen can depend on the degree of congruity or compatibility between corresponding elements of the Pavlovian and instrumental expectancies, as shown here. But just how far the limits of this sort of specificity extend, and, conversely, what factors determine the extent to which expectancies will generalize, is still unknown. Despite their use in theory, the specific properties of the conditioned responses to stimuli associated with appetitive reinforcers are largely unexplored. Until such detail can be produced, the whole concept of mediating emotive states, or of reinforcer-derived expectancies, will remain little more than a theoretical convenience. 


\section{REFERENCES}

Annau, Z., \& Kamin, L. J. The conditioned emotional response as a function of the intensity of the US. Journal of Comparative and Physiological Psychology, 1961, 54, 428-432.

Azrin, N. H., \& Hake, D. F. Positive conditioned suppression: Conditioned suppression using positive reinforcers as the unconditioned stimuli. Journal of the Experimental Analysis of Behavior, 1969, 12, 167-173.

Barbaree, H. E., \& Weisman, R. G. On the failure of transfer of control from separately conducted Pavlovian conditioning to free-operant avoidance conditioning in rats. Learning and Motivation, 1975, 6, 498-511.

Barbaree, H. E., \& Weisman, R. G. Acceleration and suppression of rat's responding to avoid foot shock and tail shock. Journal of the Experimental Analysis of Behavior, 1978, 29, 253-254.

Baxter, D. J., \& Zamble, E. Attempts to transfer Pavlovian appetitive conditioning under curare to food-motivated operant responding. Bulletin of the Psychonomic Society, 1980, 15, 225-228.

Bindra, D. A motivational view of learning: Performance and behavior modification. Psychological Review, 1974, 81, 199-213.

Buack, A. H. Transfer following operant conditioning in the curarized dog. Science, 1967, 155, 201-203.

Bolles, R. C. Reinforcement, expectancy, and learning. Psychological Review, 1972, 79, 394-409.

Bolles, R. C. Learning theory. New York: Holt, Rinehart \& Winston, 1975.

Bolles, R. C., \& Grossen, N. E. The noncontingent manipulation of incentive motivation. In J. H. Reynierse (Ed.), Current issues in animal learning. Lincoln: University of Nebraska Press, 1970.

Bower, G., \& Grusec, T. Effect of prior Pavlovian discrimination training upon learning an operant discrimination. Journal of the Experimental Analysis of Behavior, 1964, 7, 401-404.

Bower, G., \& Kaufman, R. Transfer across drives of the discriminative effect of a Pavlovian conditioned stimulus. Journal of the Experimental Analysis of Behavior, 1963, 6, 445-448.

Estes, W. K. Discriminative conditioning. I. A discriminative property of conditioned anticipation. Journal of Experimental Psychology, 1943, 32, 150-155.

Estes, W. K., \& Skinner, B. F. Some quantitative properties of anxiety. Journal of Experimental Psychology, 1941, 29, $390-400$.

Hawkins, T. D., \& Pliskoff, S. S. Brain-stimulation intensity, rate of self-stimulation, and reinforcement strength: An analysis through chaining. Journal of the Experimental Analysis of Behavior, 1964, 7, 285-288.

Hearst, E. Pavlovian conditioning and directed movements. In G. H. Bower (Ed.), The psychology of learning and motivation (Vol. 9). New York: Academic Press, 1975.

Henton, W. W., \& Brady, J. V. Operant acceleration during a pre-reward stimulus. Journal of the Experimental Analysis of Behavior, 1970, 13, 205-209.

Henrnstein, R. J., \& Morse, W. H. Some effects of responseindependent positive reinforcement on maintained operant behavior. Journal of Comparative and Physiological Psychology, $1957,50,461-467$.

Jenkins, H. M., \& Moore, B. R. The form of the autoshaped response with food or water reinforcers. Journal of the Experimental Analysis of Behavior, 1973, 20, 163-181.

KAMIN, L. J. Temporal and intensity characteristics of the conditioned stimulus. In W. F. Prokasy (Ed.), Classical conditioning: A symposium. New York: Appleton-Century-Crofts, 1965.

Kononski, J. Integrative activity of the brain. Chicago: University of Chicago Press, 1967.

LoLoRdo, V. M. Facilitation of food-reinforced responding by a signal for response-independent food. Journal of the Experimental Analysis of Behavior, 1971, 15, 49-55.

Lolordo, V. M., McMillan, J. C., \& Riley, A. L. The effects upon food-reinforced pecking and treadle-pressing of auditory and visual signals for response-independent food. Learning and Motivation, 1974, 5, 24-41.

Mackintosh, N. J. The psychology of animal learning. London: Academic Press, 1974.

Meltzer, D., \& Brahlek, J. A. Conditioned suppression and enhancement with the same positive UCS: An effect of CS duration. Journal of the Experimental Analysis of Behavior, 1970, 13, 67-73.

Overmier, J. B., Bull, J. A., III, \& Trapold, M. A. Discriminative cue properties of different fears and their role in response selection in dogs. Journal of Comparative and Physiological Psychology, 1971, 76, 478-482.

Pavlov, I. P. Conditioned reflexes. Oxford: Oxford University Press, 1927.

Peterson, G. B., Ackil, J., Frommer, G. P., \& Hearst, E. Conditioned approach and contact behavior toward signals for food or brain-stimulation reinforcement. Science, 1972, 177, 1009-1011.

Pliskoff, S. S., Wright, J. E., \& Hawkins, T. D. Brain stimulation as a reinforcer: Intermittent schedules. Journal of the Experimental Analysis of Behavior, 1965, 8, 75-88.

Resconla, R. A. Probability of shock in the presence and absence of CS in fear conditioning. Journal of Comparative and Physiological Psychology, 1968, 66, 1-5.

Rescorla, R. A., \& Solomon, R. L. Two-process learning theory: Relationships between Pavlovian conditioning and instrumental learning. Psychological Review, 1967, 74, 151-182.

Scosie, S. E. Interaction of an aversive Pavlovian conditional stimulus with aversively and appetitively motivated operants in rats. Journal of Comparative and Physiological Psychology, $1972,79,171-188$.

Staddon, J., \& Simmelhag, V. L. The "superstition" experiment: A re-examination of its implications for the principles of adaptive behavior. Psychological Review, 1971, 78, 3-43.

Trapold, M. A. Are expectancies based on different positive reinforcing events discriminably different? Learning and Motivation, 1970, 1, 129-140.

Trapold, M. A., \& Carlson, J. G. Proximity of manipulandum and food cup as a determinant of the generalized SD effect. Psychonomic Science, 1965, 2, 327-328.

Trapold, M. A., \& Overmier, J. B. The second learning process in instrumental learning. In A. H. Black \& W. F. Prokasy (Eds.), Classical conditioning II: Current research and theory. New York: Appleton-Century-Crofts, 1972.

Trapold, M. A., \& Winokur, S. Transfer from classical conditioning and extinction to acquisition, extinction, and stimulus generalization of a positively reinforced response. Journal of Experimental Psychology, 1967, 73, 517-525.

VAN Dyne, G. C. Conditioned suppression with a positive US in the rat. Journal of Comparative and Physiological Psychology, 1971, 77, 131-135.

WiElkiewicz, R. M. Effects of CSs for food and water upon rats barpressing for different magnitudes of food reinforcement. Animal Learning \& Behavior, 1979, 7, 246-250.

Wolin, B. R. Difference in manner of pecking a key between pigeons reinforced with food and with water. In A. C. Catania (Ed.), Contemporary research in operant behavior. Glenview, Ill: Scott, Foresman, 1968.

ZAMBLE, E. Conditioned motivational patterns in instrumental responding. Journal of Comparative and Physiological Psychology, 1969, 69, 536-543.

Zamble, E. Pavlovian appetitive conditioning under curare in rats. Animal Learning \& Behavior, 1974, 2, 101-105.

ZENER, $\mathrm{K}$. The significance of behavior accompanying conditioned salivary secretion for theories of the conditioned response. American Journal of Psychology, 1937, 50, 384-403.

(Manuscript received January 13, 1981; revision accepted for publication November 28,1981 .) 